\title{
About the Series
}

Latin America Otherwise: Languages, Empires, Nations is a critical series. It aims to explore the emergence and consequences of concepts used to define "Latin America" while at the same time exploring the broad interplay of political, economic, and cultural practices that have shaped Latin American worlds. Latin America, at the crossroads of competing imperial designs and local responses, has been construed as a geocultural and geopolitical entity since the nineteenth century. This series provides a starting point to redefine Latin America as a configuration of political, linguistic, cultural, and economic intersections that demand a continuous reappraisal of the role of the Americas in history, and of the ongoing process of globalization and the relocation of people and cultures that have characterized Latin America's experience. Latin America Otherwise: Languages, Empires, Nations is a forum that confronts established geocultural constructions, that rethinks area studies and disciplinary boundaries, that assesses convictions of the academy and of public policy, and that, correspondingly, demands that the practices through which we produce knowledge and understanding about and from Latin America be subject to rigorous and critical scrutiny.

Colonial administration and the postcolonial nation-state in Latin America followed a different pattern when compared with colonized countries in Asia and Africa. The early decolonization from Spain and Portugal placed most Latin American countries in peculiar positions with emerging imperial powers such as England and France. Latin America's incipient nation-states, indirectly dependent on these dominant European powers, were in turn shaped by these relations. Peter M. Beattie's book traces the gloomy picture of eighty years of nation-state formation in Brazil, focusing on military history and race relations.

By telling the story of Domingos, the son of an Angolan slave and a Portuguese nobleman, Beattie unravels the conflicting intersections of the army code of honor, the racial prejudices underlying the value system of 
postcolonial Brazil, and the constitution of its civil society. In the forming Brazilian State, "whiteness" was associated with honor, prestige, and wealth. However, in the international order of the period under study, the distinction between Anglo and Latin whites was being made, as "whiteness" in Brazil was not the same as "whiteness" in the United States. This superb study of the relationships between honor, race, and the army in Brazil also offers a wealth of information and ideas on the configuration of racial prejudices in Latin countries during the second half of the nineteenth and the first half of the twentieth century. 
To my mother,

Jean O'Connor Beattie

To the memories of my father,

Francis Martin Beattie

And my sister,

Natalie Childress Beattie 

Man to the hills, woman to the shore.

- Gaelic proverb

Cuchulain stirred,

Starred on the horses of the sea, and heard

The cars of battle and his own name cried;

And fought with the invulnerable tide.

-W. B. Yeats, "Cuchulain's Fight with the Sea"

I shouldered a kind of manhood

Stepping in to lift the coffins

of dead relations.

-Seamus Heaney, "Funeral Rites” 
